\title{
Learning from Team and Group Diversity: Nurturing and Benefiting from our Heterogeneity
}

$\begin{array}{ll}\begin{array}{l}\text { Michael Muller } \\ \text { IBM Research } \\ \text { michael_muller@us.ibm.com }\end{array} & \begin{array}{l}\text { Nigini Oliveira } \\ \text { University of Washington } \\ \text { nigini@cs.washington.edu }\end{array} \\ \begin{array}{l}\text { Susan R. Fussell } \\ \text { Cornell University } \\ \text { sfussell@cornell.edu }\end{array} & \begin{array}{l}\text { Katharina Reinecke } \\ \text { University of Washington } \\ \text { reinecke@cs.washington.edu }\end{array} \\ \begin{array}{l}\text { Ge Gao } \\ \text { University of Maryland } \\ \text { gegao@umd.edu }\end{array} & \begin{array}{l}\text { Lionel Robert Jr } \\ \text { University of Michigan } \\ \text { Iprobert@umich.edu }\end{array} \\ \begin{array}{l}\text { Pamela J. Hinds } \\ \text { Stanford University } \\ \text { phinds@stanford.edu }\end{array} & \text { Kanya (Pao) Siangliulue } \\ \text { Harvard University } \\ \text { paopow@seas.harvard.edu }\end{array}$

Paste the appropriate copyright/license statement here. ACM now supports three different publication options:

- ACM copyright: ACM holds the copyright on the work. This is the - Aistorical approach.

- License: The author(s) retain copyright, but ACM receives an - License: The author(s) retain

exclusive publication license. - Open Access: The author(s) wish to pay for the work
access. The additional fee must be paid to ACM.

This text field is large enough to hold the appropriate release statement assuming it is single-spaced in Verdana 7 point font. Please do not change the size of this text box.

Each submission will be assigned a unique DOI string to be included here.

\author{
Volker Wulf \\ University of Siegen \\ volker.wulf@uni-siegen.du \\ Chien-Wen Yuan \\ National Taiwan Normal University \\ tinachienwenyuan@gmail.com
}

\begin{abstract}
By 2019, diversity is an established fact in most workplaces, teams, and work-groups, presenting both old and new challenges to CSCW in terms of team structure and technological
\end{abstract} supports for increasingly diverse teams. The research literature on diversity and teams has examined many definitions and attributes of diversity, and has described different types of teams, tasks, and measures, with contrasting and even contradictory results. Diversity becomes a strength in some studies, and a burden in others. The literature is similarly complex regarding individual and organizational approaches to realize those strengths, or to mitigate those burdens. In this workshop, we collectively take stock of these complex findings; we consider the several theoretical and methodological efforts to organize these findings; and we propose new research directions to address the "diversity of diversity studies."

\section{Author Keywords}

Diversity; Inclusion; Teams; Team/group diversity; Work-groups. 


\section{Draft Workshop Agenda}

Welcome and Introductions.

Who are we? How can we help each other?

Diversity Attributes. What human and contextual aspects have we studied in relation to diversity? Who is left out? How can we include them?

Measuring Diversity. What tasks, artifacts, surveys, etc. have we used to study diversity? What are we missing?

Theorizing Diversity and Difference. How have we made sense of the complex patterns and outcomes in diversity studies?

Notes:

Timing of each topic will depend on position papers.

We will work in plenary or small groups, depending on convergence or divergence of participants' interests.

Table 1. Draft workshop aqenda.

\section{ACM Classification Keywords}

H.5.3 Group and organizational interfaces: CSCW.

\section{Introduction}

Teams have become increasingly diverse over time [22, 24]. This diversity offers both opportunities and challenges to CSCW. The research literature about the diversity of teams and work-groups is complex, leaving many questions unresolved. Scholars in $\mathrm{HCI}$ and $\mathrm{CSCW}$ have examined the factors that can strengthen diverse teams $[4,6,10,11,12,19,26,37,39,41,43,50$, 51] - often with contrasting "lessons learned." This workshop brings CSCW and $\mathrm{CHI}$ people together to assess the current state-of-the-research, and to propose ways forward.

\section{Background}

Supporting Diversity among Teams and Workgroups Hui and Farnham advocated designing for gender inclusion [24]. Robert and You discussed mitigations for perceived interpersonal differences across distances through communication technologies [41], within the context of the research tradition that has followed the landmark "distance matters" paper of Olson and Olson [33]. Oliveira and colleagues [31] compared crossnational engagement in an open online collaboration site and identified barriers for non-Western Stack Overflow participants to contribute and feel part of the Stack Overflow community.

Less than two months before the submission of this workshop proposal, Scheuerman et al. published a set of proposed HCI Guidelines for gender equity and inclusivity [44].
Why Should Diversity be Influential?

Diversity has been hypothesized to have both beneficial and harmful effects on team processes and outcomes.

Diversity Considered Beneficial

Advocates of the beneficial effects of diversity see value in the combination of diverse ideas, sometimes strategically managed as a source of tension and resolution [39]. Jackson and Joshi, and Watson et al., note the importance of having more ideas to combine $[25,52]$ - especially across institutions [22]. As Lorde noted [30], discussions, disagreements, and resolutions may be particularly valuable $[2,27]$.

\section{Diversity Considered Harmful}

However, diversity has also been conceived as divisive and problematic. If there are too many dissimilar people on a team, they may have trouble to achieve common ground $[9,46,47]$, shared vocabulary [5], or reduction in problems in communication, coordination, and conflict management $[19,20,21]$.

Teams with very dissimilar member may encounter "faultlines" [20,36] - i.e., divisive subgroups that engage in stereotyping and cliquishness [50], leading to confusion, stress, and conflict $[23,50]$. These processes have been hypothesized to depend on the operation of social identity or self-categorization $[2,13$, $28,40,45]$ - i.e., the occurrence of homophily among micro-ingroups within a team.

We have, then, two contrasting sets of predictions and explanations. What has the research literature found? 
Temporal Aspects of Team Diversity

These positive and negative influences may also depend on the point-in-time of a longitudinal team process, resulting from greater mutual knowledge among team members $[18,52]$, changes in knowledgetransfer relations among novices and experts [54], or enhanced cultural adaptations $[9,14]$ over time.

\section{Diversity Measures and Outcomes}

Among multiple complicating factors, the research literature has examined the positive and negative contributions of team diversity to documents [49] and to many other forms of collective production, including WikiProject Film community articles [37], team performance in a large-scale online game [7] or decision-making [42], laboratory tasks of mapnavigation [12], laboratory studies of brainstorming [51], team performance $[41,50]$, individual performance in a team setting [15], self-reports via surveys [10], and senior-executive ratings [10]. Some of these tasks were consequential for participants e.g., $[20,21,22,41,49,50]$, while other tasks were laboratory exercises for people who had no stake in the outcomes $[12,51]$. Some of the activities produced tangible outcomes [37, 41, 49,50,51], but other tasks led primarily to measurements rather than to outputs $[10,12,15]$.

In addition to the relatively concrete outcomes reported above, other papers have reported more social and perspectival factors, such as trust [15], cultural surprise [1], cohesion, attribution [1], collaboration readiness [4], team identification [41], social identity [13], sense of inclusion [24], and the perception of diversity $[15,41]$.
Finally, the metric for assessing diversity are not a settled matter. Wilcox proposed diverse metrics for both nominal (qualitative) diversity and quantitative diversity [53]. Harrison and Klein updated and extended this treatment [17]. Muller et al. recently proposed theory-based sub-metrics for nominal diversity [31].

\section{Workshop Intentions}

In view of these ranges of paradigms, outcomes, measurements, and settings, we should perhaps not be surprised to find reports of both positive $[19,16,26$, $35,38]$ and negative $[6,29,34,48]$ contributions of diversity across wide ranges of outcomes, contexts, and measurements [23]. By working together, we may find that there are distinct patterns among the effects of diversity, and that some of those patterns depend on task, participants' stakes in the outcomes, and methods of measurement.

To do this, we will solicit position papers from CSCW researchers and from people outside of CSCW. Position papers may address methods, findings, or theories related to diversity and diversity studies. While we have sketched a workshop agenda in Table 1, we will reshape that agenda based on participants' interests, and upon our sense of how to organize a review of diversity studies. We anticipate that our ideas for this organization will change in response to the position papers. We will be particularly interested to help the members of the workshop to find new challenges and new collaborators.

\section{Workshop Goal}

In collaboration with interested members of the workshop, we hope to write a review paper that 
describes the current state of diversity studies, and that proposes new challenges or problems to be solved. We hope to publish the review paper in a future CSCW, or TOCHI or the Journal of CSCW.

\section{Operational Details}

We will publicize the workshop through email distribution lists, meta pages, and other personal networks.

We will set up a workshop website.

We will circulate position papers to workshop members in advance. Our intention is not to present a series of position papers, but rather to build new understandings and propose new research topics.

The workshop is one full day.

\section{Organizers}

Susan R. Fussell is professor and director of graduate studies in Communications at Cornell University, Her research focuses on interpersonal communication in face-to-face and computer-mediated contexts, including intercultural computer-mediated communication and multi-lingual communication.

Ge Gao is an Assistant Professor in the College of Information Studies (iSchool) at the University of Maryland, College Park. She conducts research that examines the joint effects of technology use and diversity on global teamwork.

Pamela J. Hinds is Professor and Director of the Center on Work, Technology, and Organization in the
Department of Management Science and Engineering, Stanford University. She studies the interplay between technology and collaboration, especially on teams. Pamela has conducted extensive research on the dynamics of geographically distributed work teams, particularly those spanning national boundaries, and more generally on cross-boundary teams.

Michael Muller works as a research staff member at IBM Research. His work addresses collaboration and collaborative systems, diversity among paper coauthors, human-centered data science, and social justice.

Nigini Oliveira is an HCI researcher with interest in studying, designing, and building social computing systems for cultural diversities. He is now a Postdoctoral fellow at the Paul G. Allen School for Computer Science and Engineering at the University of Washington.

Katharina Reinecke is an assistant professor at the Paul G. Allen School of Computer Science \& Engineering at the University of Washington, where she researches diversity barriers in technology, often using large-scale online experiments.

Lionel Robert Jr works as an associate professor at the School of Information (UMSI) at the University of Michigan. His work addresses online collaborations and human interactions with autonomous systems.

Pao Siangliulue develops and studies creativity support tools. She works at B12 where she leads an engineering team that builds tools to support collaboration in creative teams. 
Volker Wulf is professor of Information Systems and director of Media Resource Institute at University of Siegen. His research includes IT system design in realworld contexts, including cooperative systems and community-based support, often in an inter-cultural setting, with emphases on diversity and genders.

Chien-Wen Yuan is an assistant professor at the Graduate Institute of Library and Information Studies, NTNU in Taiwan. Her work revolves around computermediated communication and group collaboration for social connection and knowledge transfer.

\section{References}

1. Ban Al-Ani, Erik Trainer, David Redmiles, and Erik Simmons. 2012. Trust and surprise in distributed teams: towards an understanding of expectations and adaptations. In Proceedings of the 4th international conference on Intercultural Collaboration. ACM, ACM, 97-106.

2. Blake E Ashforth and Fred Mael. 2004. Social identity theory and the organization. Organizational identity: A reader (2004), 134-160.

3. Charles R Bantz. 1993. Cultural diversity and group cross-cultural team research. J. App. Comm. Res. 21(1), 1-20.

4. Pernille Bjørn, Morten Esbensen, Rasmus Eskild Jensen, and Stina Matthiesen. 2014. Does distance still matter? Revisiting the CSCW fundamentals on distributed collaboration. ACM Transactions on Computer-Human Interaction (TOCHI) 21, 5 (2014), 27.

5. Ron Boschma. 2005. Proximity and innovation: a critical assessment. Regional studies 39, 1 (2005), $61-74$.

6. Jilin Chen, Yuqing Ren, and John Riedl. 2010. The effects of diversity on group productivity and member withdrawal in online volunteer groups. In
Proceedings of the SIGCHI conference on human factors in computing systems. ACM, 821-830.

7. Ziqiang Cheng, Yang Yang, Chenhao Tan, Denny Cheng, Alex Cheng, and Yueting Zhuang. 2019. What Makes a Good Team? A Large-scale Study on the Effect of Team Composition in Honor of Kings. In The World Wide Web Conference. ACM, 26662672.

8. Laku Chidambaram and Judith A. Kautz. 1993. Defining common ground: managing diversity through electronic meeting systems. In Proc. ICIS. 1993, 1-11.

9. Catherine Durnell Cramton and Pamela J. Hinds. 2014. An embedded model of cultural adaptation in global teams. Org. Sci. 25(4), 1056-1081.

10. Jonathon N Cummings. 2004. Work groups, structural diversity, and knowledge sharing in a global organization. Management science 50, 3 (2004), 352-364.

11. Jonathon N Cummings and Sara Kiesler. 2005. Collaborative research across disciplinary and organizational boundaries. Social studies of science 35, 5 (2005), 703-722.

12. E Ilana Diamant, Susan R Fussell, and Fen-Ly Lo. 2009. Collaborating across cultural and technological boundaries: Team culture and information use in a map navigation task. In Proceedings of the 2009 international workshop on Intercultural collaboration. ACM, ACM, 175-184.

13. Shelly D Farnham and Elizabeth F Churchill. 2011. Faceted identity, faceted lives: social and technical issues with being yourself online. In Proceedings of the ACM 2011 conference on Computer supported cooperative work. ACM, 359-368.

14. Ge Gao and Susan R. Fussell. 2017. A kaleidoscope of languages: When and how non-Native English speakers shift between English and their Native language during multilingual teamwork. In 
Proceedings of the 2017 CHI Conference on Human Factors in Computing Systems (CHI '17), 760-772.

15. Gary Garrison, Robin L Wakefield, Xiaobo Xu, and Sang Hyun Kim. 2010. Globally distributed teams: The effect of diversity on trust, cohesion and individual performance. ACM SIGMIS Database: the database for Advances in Information Systems 41, 3 (2010), 27-48.

16. Lucy L Gilson, Hyoun Sook Lim, Margaret M Luciano, and Jin Nam Choi. 2013. Unpacking the cross-level effects of tenure diversity, explicit knowledge, and knowledge sharing on individual creativity. Journal of Occupational and

Organizational Psychology 86, 2 (2013), 203-222.

17. David A. Harrison and Katherine J. Klein. 2007. What's the difference? Diversity constructs as separation, variety, or disparity in organizations. Academy of Management Review 32, 1199-1228.

18. Harrison, D. A., Price, K. H., \& Bell, M. P. (1998). Beyond relational demography: Time and the effects of surface-and deep-level diversity on work group cohesion. Academy of Management Journal 41, 96-107.

19. Pamela J Hinds and Diane E Bailey. 2003. Out of sight, out of sync: Understanding conflict in distributed teams. Organization science 14, 6 (2003), 615-632.

20. Pamela J. Hinds, Tsedal B. Neeley, and Catherine Durnell Cramton. 2014. Language as a lightning rod: Power contests, emotion regulation, and subgroup dynamics in global teams. J. Bus. Stud. 45(5), 536-561.

21. Pamela J. Hinds, Daniela Retelny, \& Catherine Durnell Cramton. 2015. In the flow, being heard, and having opportunities: Sources of power and power dynamics in global teams. Proceedings of the ACM Conference on Computer Supported Cooperative Work (CSCW).
22. Charles C Hinnant, Besiki Stvilia, Shuheng Wu, Adam Worrall, Gary Burnett, Kathleen Burnett,

Michelle M Kazmer, and Paul F Marty. 2012.

Author-team diversity and the impact of scientific publications: Evidence from physics research at a national science lab. Library \& Information Science Research 34, 4 (2012), 249-257.

23. Sujin K Horwitz and Irwin B Horwitz. 2007. The effects of team diversity on team outcomes: A meta-analytic review of team demography. Journal of Management 33, 6 (2007), 987-1015.

24. Julie S Hui and Shelly D Farnham. 2016. Designing for Inclusion: Supporting Gender Diversity in Independent Innovation Teams. In Proceedings of the 19th International Conference on Supporting Group Work. ACM, 71-85.

25. Susan E Jackson and Aparna Joshi. 2004. Diversity in social context: a multi-attribute, multilevel analysis of team diversity and sales performance. Journal of Organizational Behavior: The International Journal of Industrial, Occupational and Organizational Psychology and Behavior 25, 6 (2004), 675-702.

26. Karen A Jehn, Gregory B Northcraft, and Margaret A. Neale. 1999. Why differences make a difference: A field study of diversity, conflict and performance in workgroups. Administrative Science Quarterly 44, 4 (1999), 741-763.

27. Eric Kearney, Diether Gebert, and Sven C Voelpel. 2009. When and how diversity benefits teams: The importance of team members' need for cognition. Academy of Management Journal 52, 3 (2009), 581-598.

28. Josephine Chinying Lang. 2004. Social context and social capital as enablers of knowledge integration. Journal of knowledge management 8, 3 (2004), 89-105.

29. James R Larson, Caryn Christensen, Ann S Abbott, and Timothy M Franz. 1996. Diagnosing groups: 
charting the flow of information in medical decision-making teams. Journal of personality and social psychology 71, 2 (1996), 315.

30. Audre Lorde. 1978. The black unicorn. Norton.

31. Michael Muller, Casey Dugan, Aabhas Sharman, and Narendra Nath Joshi. Submitted. Does diversity among authors contribute to acceptance of conference papers? Submitted to GROUP 2020.

32. Nigini Oliveira, Michael Muller, Nazareno Andrade, and Katharina Reinecke. 2018. The Exchange in StackExchange: Divergences between Stack Overflow and its Culturally Diverse Participants. Proc. ACM Hum.-Comput. Interact. 2, CSCW, Article 130

33. Gary M Olson and Judith S Olson. 2000. Distance matters. Human-Computer Interaction 15, 2-3 (2000), 139-178.

34. Charles A O'Reilly III, David F Caldwell, and William P Barnett. 1989. Work group demography, social integration, and turnover. Administrative Science Quarterly (1989), 21-37.

35. Scott E Page. 2008. The Difference: How the Power of Diversity Creates Better Groups, Firms, Schools, and Societies-New Edition. Princeton University Press.

36. Ramón Rico, Eric Molleman, Miriam SánchezManzanares, and Gerben S Van der Vegt. 2007 The effects of diversity faultlines and team task autonomy on decision quality and social integration. Journal of Management 33, 1 (2007), 111-132.

37. Lionel Robert and Daniel M Romero. 2015. Crowd size, diversity and performance. In Proceedings of the 33rd Annual ACM Conference on Human Factors in Computing Systems. ACM, 1379-1382.

38. Lionel P Robert. 2013. A multi-level analysis of the impact of shared leadership in diverse virtual teams. In Proceedings of the 2013 conference on
Computer supported cooperative work. ACM, 363374.

39. Lionel P Robert. 2016. Far but near or near but far?: The effects of perceived distance on the relationship between geographic dispersion and perceived diversity. In Proceedings of the $2016 \mathrm{CHI}$ Conference on Human Factors in Computing Systems. ACM, 2461-2473.

40. Lionel P Robert Jr, Alan R Dennis, and Manju K Ahuja. 2008. Social capital and knowledge integration in digitally enabled teams. Information Systems Research 19, 3 (2008), 314-334.

41. Lionel P. Robert, Alan Dennis, and Manju Ahuja 2018. Differences are different: Examining the effects of communication media on the impacts of racial and gender diversity in decision-making teams, Information Systems Research (ISR), 29(3), 525-545.

42. Lionel P Robert Jr and Sangseok You. 2018 Disaggregating the Impacts of Virtuality on Team Identification. In Proceedings of the 2018 ACM Conference on Supporting Groupwork. ACM, 309321.

43. Terje Samuelsen, Ricardo Colomo-Palacios, and Monica Kristiansen. 2016. Learning software project management in teams with diverse backgrounds. In Proceedings of the Fourth International Conference on Technological Ecosystems for Enhancing Multiculturality. ACM, 127-131.

44. Morgan Klaus Scheuerman, Katta Spiel, Oliver L. Haimson, Foad Hamidi, and Stacy M. Branham. 2019. HCI guidelines for gender equity and inclusivity. https://www.morgan-klaus.com/sigchigender-guidelines.

45. Craig R Scott. 2007. Communication and social identity theory: Existing and potential connections in organizational identification research. Communication Studies 58, 2 (2007), 123-138. 
46. Pnina Shachaf. 2008. Cultural diversity and information and communication technology impacts on global virtual teams: An exploratory study. Information \& Management 45, 2 (2008), 131-142.

47. Frank Siebdrat, Martin Hoegl, and Holger Ernst. 2009. How to manage virtual teams. MIT Sloan Management Review 50, 4 (2009), 63.

48. Garold Stasser, Laurie A Taylor, and Coleen Hanna. 1989. Information sampling in structured and unstructured discussions of three-and six-person groups. Journal of personality and social psychology 57, 1 (1989), 67.

49. Besiki Stvilia, Charles C Hinnant, Katy Schindler, Adam Worrall, Gary Burnett, Kathleen Burnett, Michelle M Kazmer, and Paul F Marty. 2011. Composition of scientific teams and publication productivity at a national science lab. Journal of the American Society for Information Science and Technology 62, 2, 270-283.

50. Bogdan Vasilescu, Daryl Posnett, Baishakhi Ray, Mark GJ van den Brand, Alexander Serebrenik, Premkumar Devanbu, and Vladimir Filkov. 2015. Gender and tenure diversity in GitHub teams. In Proceedings of the 33rd annual ACM conference on human factors in computing systems. ACM, 37893798.

51. Hao-Chuan Wang, Susan R Fussell, and Dan Cosley. 2011. From diversity to creativity: Stimulating group brainstorming with cultural differences and conversationally-retrieved pictures. In Proceedings of the ACM 2011 conference on Computer supported cooperative work. ACM, 265274.

52. Warren E Watson, Kamalesh Kumar, and Larry K Michaelsen. 1993. Cultural diversity's impact on interaction process and performance: Comparing homogeneous and diverse task groups. Academy of management journal 36, 3 (1993), 590-602.

53. Wilcox, Allen R.1973, Indices of qualitative variation and political measurement. The Western Political Quarterly 26 (2): 325-343.

54. Yang, C. L., Yuan, C. W. T., Wang, T. Y., \& Wang, H. C. 2018. Knowing that you know what I know helps?: Understanding the effects of knowledge transparency in online knowledge transfer. Proceedings of the ACM on HumanComputer Interaction 2, 189. 